\title{
Modeling and Characteristic Analysis of a Solar Parabolic Trough System: Thermal Oil as the Heat Transfer Fluid
}

\author{
Zhai Rongrong, Yang Yongping, Yan Qin, and Zhu Yong \\ School of Energy Power and Mechanical Engineering, North China Electric Power University, Beijing 102206, China \\ Correspondence should be addressed to Zhai Rongrong; zhairongrong@gmail.com
}

Received 31 January 2013; Revised 27 May 2013; Accepted 7 July 2013

Academic Editor: Shuhui Li

Copyright ( 2013 Zhai Rongrong et al. This is an open access article distributed under the Creative Commons Attribution License, which permits unrestricted use, distribution, and reproduction in any medium, provided the original work is properly cited.

\begin{abstract}
The thermal oil is applied as the heat transfer fluid in a solar parabolic trough collector system. Firstly, the system dynamic model was established and validated by the real operating data in typical summer and spring days in references. Secondly, the alteration characteristics of different solar radiation, inlet water temperature and flow rate, and collectors' area and length are analyzed and compared with the normal working condition. The model can be used for studying, system designing, and better understanding of the performance of parabolic trough systems.
\end{abstract}

\section{Introduction}

Parabolic trough solar collector is a kind of line-focus concentrating solar utilizations for industry, with medium temperature, maximum working temperature $400-500^{\circ} \mathrm{C}$. According to the heat transfer fluid types in the absorber, thermal oil and water/steam are the basic sorts. Both the two systems are wildly used in generating or heating in modern industry in recent years. The solar energy generating system with thermal oil as the heat transfer fluid, called SEGS, has been developed in several countries, especially in the USA. Therefore, the generated green electricity has increased the impetus of future research and development.

Some of the published papers have studied the modeling and analysis of the heat transfer process of the thermal oil in parabolic trough collector systems. The one-dimension parabolic trough collector model had been developed by Odeh et al. [5], including synthetic oil and water/steam as the working fluid. The created model can be used to predict the performance of the collector. Rolim et al. [6] introduced an analytic model for a solar thermal electric generating system with parabolic trough collectors. The energy conversion of solar radiation into thermal power along the absorber tube of the parabolic collector is studied, taking into account the nonlinearity of heat losses and its dependence on the local temperature. The simulated results have been compared with experimental data. García-Valladares and Velázquez [7] developed detailed numerical simulations of thermal and fluid-dynamic behaviors of a single-pass and double-pass solar parabolic trough collector. The single-pass solar device numerical model has been carefully validated by experimental data. The parabolic trough collector and the main generating systems of the SEGS VI solar thermal oil power plant in California have been modeled by Stuetzle et al. [1,2]; the control algorithms were established in MATLAB to control outlet temperature and flow rate. The one-dimension and twodimension thermal oil solar parabolic collectors' models were developed using EES software and validated by experimental data [8]. The detailed numerical simulation model of a singlepass and double-pass solar parabolic trough collector has been developed and validated by experimental data obtained from Sandia National Laboratories [7].

However, the heat transfer has been analyzed in the above papers, but it has not been studied in detail in variable working conditions in these papers. The novelty of this paper lies in that it is focused on the details of heat transfer process with times along the flow direction, especially in the variable working conditions.

In this paper, the Euler transformation method is introduced based on the forward modeling approach to simplify the dynamic model of parabolic trough with thermal oil as the heat transfer fluid. Meanwhile, the alteration characteristics 
in different input parameters are analyzed. The alterations include solar radiation, inlet oil temperature, and inlet oil mass flow rate and collector area. The model can be used for the analysis of parabolic trough system performances in variable working conditions.

\section{Mathematic Modeling}

As shown in Figure 1, the linear parabolic concentrators are used to focus sunlight to heat the pumped heat transfer fluid in the absorber. The good light transmittance and heatdurability glass envelope are used to maintain the vacuum space between the absorber and the envelope in order to reduce heat loss and prevent corroding [9]. On the one hand, there should be vacuum between the receiver and glass envelope to reduce the heat loss. On the other hand, the luminousness should be increased by enhancing the optical performance of glass envelope. It means that the performance of luminousness and anticorrosion of glass envelope should be very good; otherwise there will be no vacuum when the glass is corroded. The heat and mass balance of absorber is listed in Figure 2.

2.1. Energy and Mass Balance Equations. According to [1-3, $8]$, the following energy and mass balance equations are used to establish the model. Equations (1) and (2) are for thermal oil; (3)-(5) and (6)-(8) about absorber and glass envelop are the same as the heat balance in direct steam generating system.

Consider

$$
\frac{\partial}{\partial t}\left(\Delta Q_{\text {oil }}(z, t)\right)=Q_{\text {oil }}(z, t)-Q_{\text {oil }}(z+\Delta z, t)+Q_{3}(z, t) \Delta z
$$

$$
\begin{gathered}
\Delta Q_{\text {oil }}(z, t)=c_{\text {oil }} \rho_{\text {oil }} A_{1} T_{\text {oil }}(z, t) \Delta z \\
\frac{\partial}{\partial t}\left(\Delta Q_{\mathrm{abs}}(z, t)\right)=\left(Q_{0}(z, t)-Q_{1}(z, t)-Q_{3}(z, t)\right) \Delta z \\
\Delta Q_{\mathrm{abs}}(z, t)=c_{\mathrm{abs}} \rho_{\mathrm{abs}} A_{\mathrm{abs}} T_{\mathrm{abs}}(z, t) \Delta z .
\end{gathered}
$$

Combining (2) and (3),

$$
\begin{aligned}
c_{\mathrm{abs}} \rho_{\mathrm{abs}} A_{\mathrm{abs}} \frac{\partial}{\partial t}\left(T_{\mathrm{abs}}(z, t)\right) & =Q_{0}(z, t)-Q_{1}(z, t)-Q_{3}(z, t) \\
\frac{\partial}{\partial t}\left(\Delta Q_{g}(z, t)\right) & =\left(Q_{1}(z, t)-Q_{2}(z, t)\right) \Delta z \\
\Delta Q_{g}(z, t) & =c_{g} \rho_{g} A_{g} T_{g}(z, t) \Delta z
\end{aligned}
$$

Combining (5) and (6),

$$
c_{g} \rho_{g} A_{g} \frac{\partial}{\partial t}\left(T_{g}(z, t)\right)=Q_{1}(z, t)-Q_{2}(z, t) .
$$

The above mentioned inlet or outlet heat $Q_{1}$ and $Q_{2}$ for absorber and glass envelope all consisted of two parts: radiation and convection. The solar radiation absorbed by per unit area absorber $Q_{0}^{\prime}[1,3,8]$ can be expressed as follows:

$$
Q_{0}^{\prime}=W \cos (\theta) f_{\theta} f_{s} f_{e} \eta_{f} \eta_{e} f_{o} .
$$

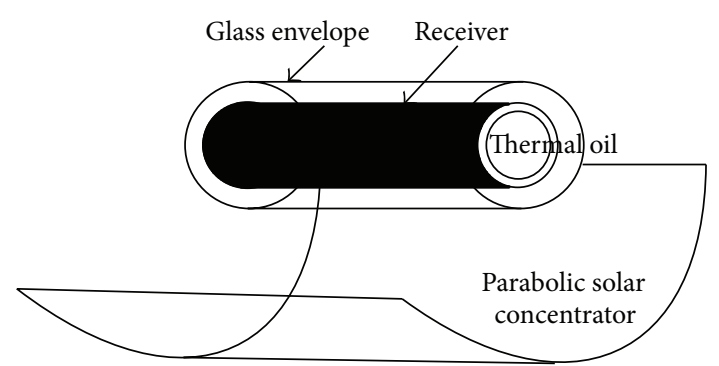

Figure 1: The schematic diagram of a parabolic trough solar collector system.

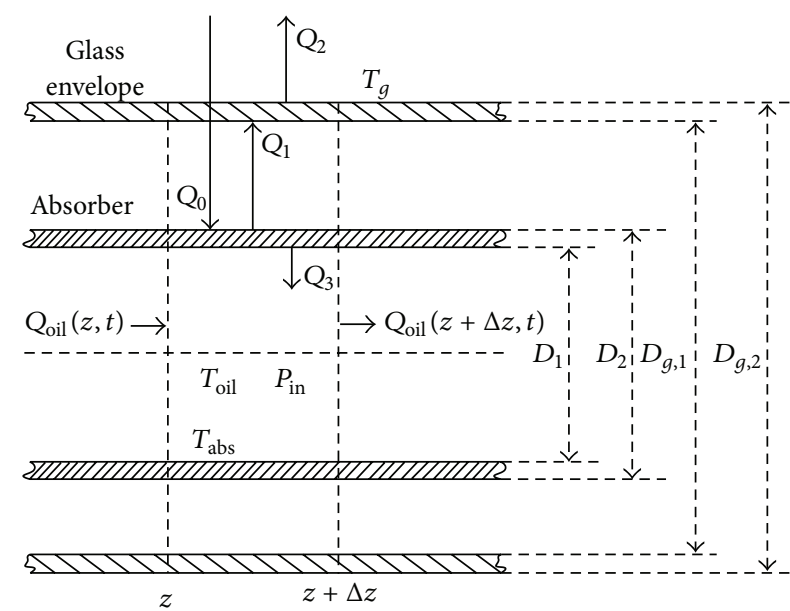

FIGURE 2: Schematic diagram of the heat transfer analysis $[1-3,8]$.

The heat absorbed by thermal oil is $Q_{3} ; Q_{3}=A_{1} h_{1}\left(T_{\mathrm{abs}}-\right.$ $\left.T_{\text {oil }}\right)$.

2.2. Equations Solving. The explicit Euler method is introduced to solve the above mentioned partial differential equations to avoid the complex solving, if the partial differential solution is used to all the individual collectors.

2.2.1. Introduction of the Explicit Euler Method. For normal ordinary differential equation (10),

$$
y^{\prime}(x)=f(x, y), \quad y(a)=y_{0}, \quad(a \leq x \leq b),
$$

where $[a, b]$ as the solution interval is partitioned equally, and $h=(b-a) / m$ as the step length. Then, the solution is marked as $x_{n}=x_{n-1}+h, n=1,2, \ldots, m$, separately. The solution of $y(x)$ at $x=x_{0}$ solved by forward difference method is as follows:

$$
y^{\prime}\left(x_{0}\right)=\frac{y\left(x_{1}\right)-y\left(x_{0}\right)}{h} .
$$

At the same time, $y\left(x_{0}\right)=f\left(x_{0}, y\left(x_{0}\right)\right)$; then,

$$
\frac{y\left(x_{1}\right)-y\left(x_{0}\right)}{h} \approx f\left(x_{0}, y\left(x_{0}\right)\right) \text {. }
$$


The approximation of $y\left(x_{1}\right)$ is expressed as (13) or (14),

$$
\frac{y_{1}-y_{0}}{h}=f\left(x_{0}, y_{0}\right)
$$

or

$$
\begin{gathered}
y_{1}=y_{0}+h \cdot f\left(x_{0}, y_{0}\right), \\
y^{\prime}\left(x_{n}\right) \approx \frac{y\left(x_{n+1}\right)-y\left(x_{n}\right)}{h}, \\
y^{\prime}\left(x_{n}\right)=f\left(x_{n}, y\left(x_{n}\right)\right) .
\end{gathered}
$$

Combining (15) and (16), the approximate forward Euler solving solution of $y\left(x_{n+1}\right)$ is as follows:

$$
y_{n+1}=y_{n}+h \cdot f\left(x_{n}, y_{n}\right) \text {. }
$$

As shown in (17), the explicit Euler method is defined, and the value of $y_{n+1}$ is calculated by $y_{n}$ directly.

2.2.2. The Euler Transformation for Thermal Oil. The energy balance equation for thermal oil based on (1) and (2) can be transformed into the following:

$$
\begin{aligned}
& c_{\text {oil }} \rho_{\text {oil }} A_{1} \frac{\partial T_{\text {oil }}(z, t)}{\partial t} \\
& \quad=c_{\text {oil }} \rho_{\text {oil }} V_{\text {oil }}\left(\frac{T_{\text {oil }}(z, t)-T_{\text {oil }}(z+\Delta z, t)}{\Delta z}\right)+Q_{3}(z, t) .
\end{aligned}
$$

Each collector is defined as a whole, and the predigesting is as follows:

$$
\frac{T_{\mathrm{oil}}(z, t)-T_{\mathrm{oil}}(z+\Delta z, t)}{\Delta z} \approx \frac{T_{\mathrm{oil}}(0, t)-T_{\mathrm{oil}}(L, t)}{L} .
$$

Combining (19) and (18), then,

$$
\begin{aligned}
& c_{\text {oil }} \rho_{\text {oil }} A_{1} \frac{d T_{\text {oil }}(L, t)}{d t} \\
& \quad=c_{\text {oil }} \rho_{\text {oil }} V_{\text {oil }} \frac{T_{\text {oil }}(0, t)-T_{\text {oil }}(L, t)}{L}+Q_{3}(z, t) .
\end{aligned}
$$

Equation (20) is sorted as follows:

$$
\frac{d T_{\mathrm{oil}}(L, t)}{d t}=V_{\mathrm{oil}} \frac{T_{\mathrm{oil}}(0, t)-T_{\mathrm{oil}}(L, t)}{L \cdot A_{1}}+\frac{Q_{3}(z, t)}{c_{\mathrm{oil}} \rho_{\mathrm{oil}} A_{1}} .
$$

For a whole collector, the outlet temperature of thermal oil is transformed by explicit Euler method as follows:

$$
\begin{aligned}
T_{\text {oil }}(L, t)= & T_{\text {oil }}(L, t)^{\prime} \\
& +\left[V_{\text {oil }} \frac{T_{\text {oil }}(0, t)-T_{\text {oil }}(L, t)^{\prime}}{L \cdot A_{1}}+\frac{Q_{3}(z, t)}{c_{\text {oil }} \rho_{\text {oil }} A_{1}}\right] \Delta t .
\end{aligned}
$$

2.2.3. The Euler Transformation for Absorber. The heat transfer expression for a whole collector absorber is as follows:

$$
c_{\mathrm{abs}} \rho_{\mathrm{abs}} A_{\mathrm{abs}} \frac{d}{d t}\left(T_{\mathrm{abs}}(L, t)\right)=\frac{Q_{0}^{\prime} \cdot W}{L}-Q_{1}-Q_{3} .
$$

The transformed equation is as follows:

$$
\begin{aligned}
& T_{\mathrm{abs}}(L, t) \\
& \quad=T_{\mathrm{abs}}^{\prime}(L, t)+\frac{Q_{0}^{\prime} \cdot S / L-Q_{1}-Q_{3}}{c_{\mathrm{abs}} \rho_{\mathrm{abs}} A_{\mathrm{abs}}} d t .
\end{aligned}
$$

2.2.4. The Euler Transformation for the Glass Envelope. The heat transfer expression of glass envelope is as follows:

$$
c_{g} \rho_{g} A_{g} \frac{d}{d t}\left(T_{g}(L, t)\right)=Q_{1}-Q_{2} .
$$

The transformed equation is as follows:

$$
T_{g}(L, t)=T_{g}^{\prime}(L, t)+\frac{Q_{1}-Q_{2}}{c_{g} \rho_{g} A_{g}} d t .
$$

The model and the program are established according to the aforesaid equations and solving approach. The schematic chart of the computer program is shown in Figures 3 and 4.

\section{Model Validation}

The operating data from real solar power plant in SEGS-VI [13 ] is used to validate the developed model. The solar collectors are LS-2, manufactured by LUZ Company. Other parameters of the power plant are listed in Table 1. The synthesized oil, THERMINOL VP-1, supplied by SOLUTIA Company, is selected as the heat transfer fluid. The operating temperatures of the thermal oil are from $12^{\circ} \mathrm{C}$ to $400^{\circ} \mathrm{C}$ in liquid and steam operating conditions. The main physical and chemical characteristics are shown in Table 2 [4].

In SEGS VI power plant, 50 groups of paratactic single circle parabolic trough collectors are the main heat resource. Each single circle is composed of 16 collectors connected in series. The outlet heated thermal oil enters into power block to heat water and generate steam, and then the cooled oil is back to each single circle by oil pump.

It is obvious that the thermal oil temperature will change along the collectors. The physical characters will change in different temperatures, according to the data from SOLUTIA company [4]. The fitted equations between parameters and temperature are gained. The relation of density $\rho_{v p-1}\left(\mathrm{~kg} / \mathrm{m}^{3}\right)$ and temperature $t$ is as follows:

$$
\begin{aligned}
\rho_{v p-1}= & -0.90797 \cdot t+0.00078116 \cdot t^{2} \\
& -2.367 \cdot 10^{-6} \cdot t^{3}+1083.25
\end{aligned}
$$




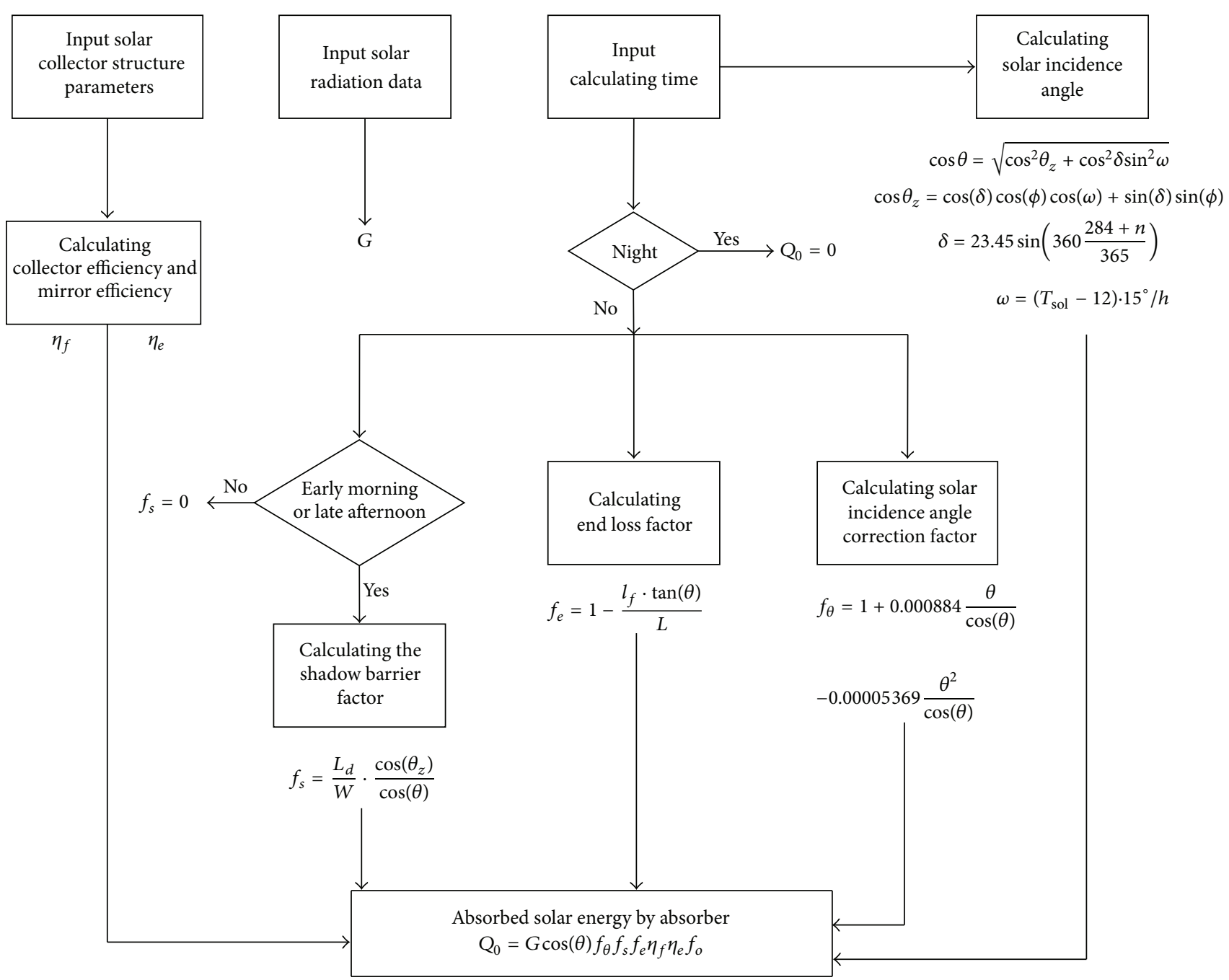

FIgURE 3: The schematic flow chart of the program to calculate the absorbed heat by absorber.

The relation of heat capacity $c_{v p-1}\left(\mathrm{~kJ} / \mathrm{kg} .{ }^{\circ} \mathrm{C}\right)$ and temperature $t$ is as follows:

$$
\begin{aligned}
c_{v p-1}= & 0.002414 \cdot t+5.9591 \cdot 10^{-6} \cdot t^{2} \\
& -2.9879 \cdot 10^{-8} \cdot t^{3} \\
& +4.4172 \cdot 10^{-11} \cdot t^{4}+1.498
\end{aligned}
$$

The relation of heat conductivity $\lambda_{v p-1}\left(\mathrm{~W} / \mathrm{m} \cdot{ }^{\circ} \mathrm{C}\right)$ and temperature $t$ is as follows:

$$
\begin{aligned}
\lambda_{v p-1}= & -8.19477 \cdot 10^{-5} \cdot t \\
& -1.92257 \cdot 10^{-7} \cdot t^{2} \\
& +2.5034 \cdot 10^{-11} \cdot t^{3} \\
& -7.2974 \cdot 10^{-15}+0.137743 .
\end{aligned}
$$

The relation of Kinematic viscosity $v_{v p-1}\left(\mathrm{~mm}^{2} / \mathrm{s}\right)$ and temperature $t$ is as follows:

$$
v_{v p-1}=e^{(544.149 /(t+114.43)-2.59578)} .
$$

Two typical operating data in spring (May 20th) and summer (June 11) days are selected as the base working conditions to validate the model. The simulated results will be compared with measured values in integral hours from 8:00 am to 7:00 $\mathrm{pm}$. All the input parameters are set the same as the real SEGS VI power plant. The comparisons are drawn in Figures 5 and 6.

Figures 5 and 6 show the comparison in spring and summer days, respectively. The solar radiation rate, oil input temperature, and flow rate are all input parameters in the model; the oil output temperature is the only output parameter. It can be seen in the two figures that the precisions are acceptable for engineering, with maximum temperature differences about $5^{\circ} \mathrm{C}$. But it is negligible in steady solar radiation days for both spring and summer working conditions. The main sources of 


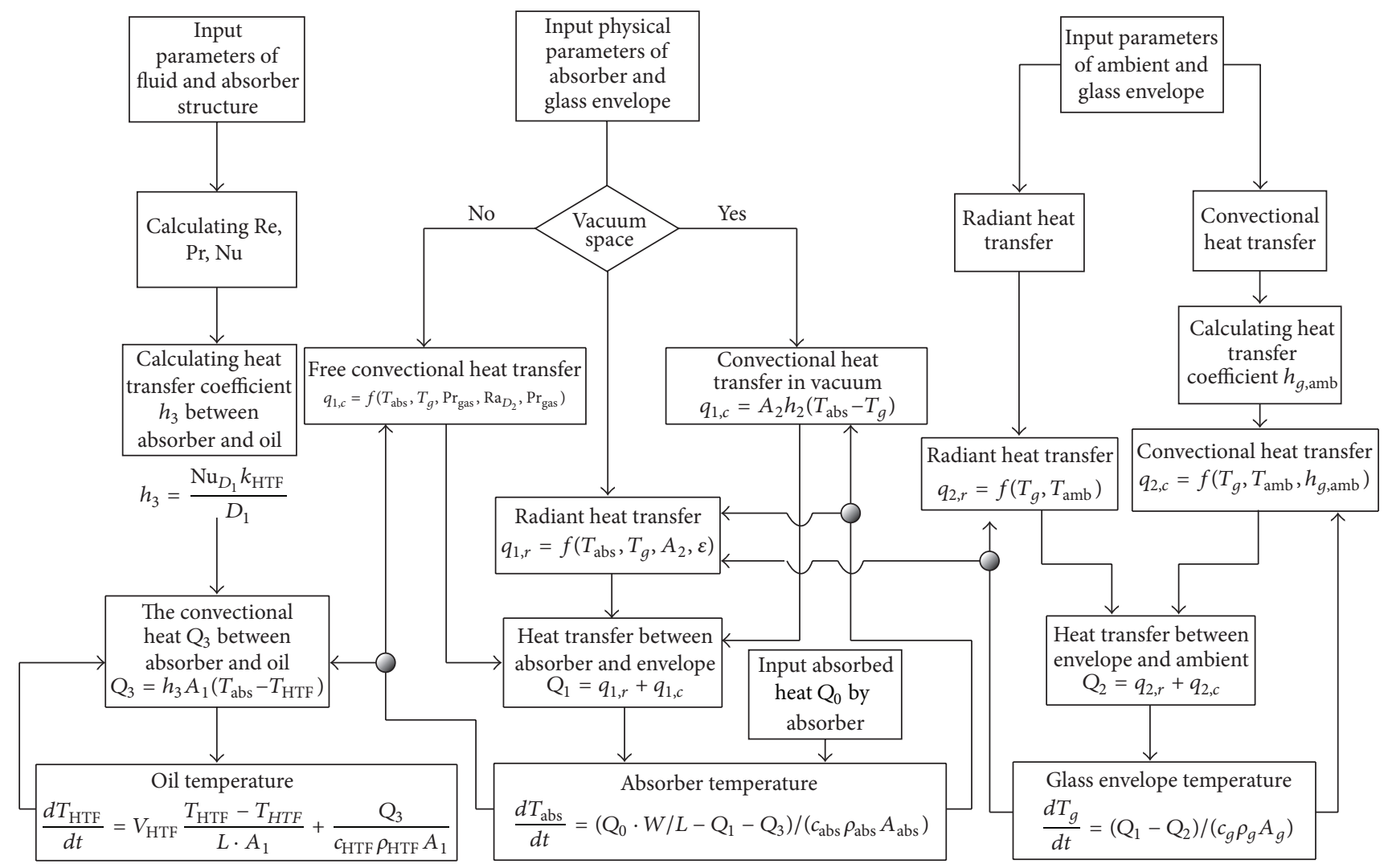

FIGURE 4: The schematic flow chart of the program to simulate the thermal oil system.

TABLE 1: The system main parameters of the SEGS VI power plant [1-3].

\begin{tabular}{|c|c|c|c|}
\hline Name & Parameters & Value & Unit \\
\hline \multirow{4}{*}{ Power block } & Name & \multicolumn{2}{|c|}{ SEGS VI in Kramer Junction, USA } \\
\hline & Net capacity & 30 & MWe \\
\hline & Designed oil temperature & 349 & ${ }^{\circ} \mathrm{C}$ \\
\hline & Solar collector area & 188000 & $\mathrm{~m}^{2}$ \\
\hline \multirow{7}{*}{ Solar collectors } & Length of single collector & 47.1 & $\mathrm{~m}$ \\
\hline & Width of single collector & 5 & $\mathrm{~m}$ \\
\hline & Area of single collector & 235 & $\mathrm{~m}^{2}$ \\
\hline & Focal length of the collector & 1.84 & $\mathrm{~m}$ \\
\hline & Focal ratio of the collector & 71 & - \\
\hline & Absorber external diameter & 70 & $\mathrm{~mm}$ \\
\hline & Envelope external diameter & 115 & $\mathrm{~mm}$ \\
\hline
\end{tabular}

differences are caused by measuring hysteresis. For the real system, the real output oil is heated along the collectors, but the measured input solar radiation is only one point. The differences will be more obvious in multivariate solar radiation working days.

\section{Characteristic Analysis}

The working condition at 12:00 am in a summer day is selected as the base condition to analyze the relations with different alterations. The alterations include solar radiation, oil inlet temperature, oil inlet flow rate, and collector length (area). The details of the base conditions are listed in Table 3.

4.1. Solar Radiation Alteration. Solar radiation alteration simulates the possible working conditions of radiation sharp changes in cloudy days or when the parabolic trough solar collectors are barred by surrounding buildings. Then based on the base working condition in Table 3, the output oil temperature will change following the changed solar radiation but maintaining other inlet parameters. Figure 7 shows the relation between output oil temperature and solar radiation 
TABLE 2: Main physical and chemical characteristics of THERMINOL VP-1 [4].

\begin{tabular}{lc}
\hline Composition & Diphenyl oxide/diphenyl \\
\hline Appearance & Clear/sediment free liquid \\
Maximum temperature & $400^{\circ} \mathrm{C}$ \\
Kinematic viscosity $\left(40^{\circ} \mathrm{C}\right)$ & $2.48 \mathrm{mmm} / \mathrm{s}$ \\
Density $\left(15^{\circ} \mathrm{C}\right)$ & $1068 \mathrm{~kg} / \mathrm{m}^{3}$ \\
Fire point & $127^{\circ} \mathrm{C}$ \\
Autoignition temperature & $621^{\circ} \mathrm{C}$ \\
Pour point & $12^{\circ} \mathrm{C}$ \\
Normal boiling point $(1013$ mbar $)$ & $257^{\circ} \mathrm{C}$ \\
Coefficient of thermal expansion & $0.00097 / /^{\circ} \mathrm{C}$ \\
$\left(200^{\circ} \mathrm{C}\right)$ & 166 \\
Average molecular weight &
\end{tabular}

TABLE 3: Parameters of the base condition.

\begin{tabular}{lcc}
\hline Parameters & Unit & Value \\
\hline Time & $\mathrm{H}: \mathrm{m}$ & $12: 00$ \\
Solar radiation & $\mathrm{W} / \mathrm{m}^{2}$ & 925 \\
Inlet oil temperature & ${ }^{\circ} \mathrm{C}$ & 285 \\
Output oil temperature & ${ }^{\circ} \mathrm{C}$ & 360 \\
Output oil mass flow rate & $\mathrm{kg} / \mathrm{s}$ & 500 \\
Collectors total area & $\mathrm{m}^{2}$ & $188000(235 \times 16 \times 50)$ \\
Collectors total length & $\mathrm{m}$ & $37600(47 \times 16 \times 50)$ \\
\hline
\end{tabular}

alterations from the range of $805 \mathrm{~W} / \mathrm{m}^{2}$ to $1045 \mathrm{~W} / \mathrm{m}^{2}$. In Figure 7, every changed solar radiation $20 \mathrm{~W} / \mathrm{m}^{2}$ will increase or reduce the output oil temperature about $2^{\circ} \mathrm{C}$. Therefore, the figure can be used to analyze or forecast the operating performances in the range of solar radiation changing working conditions.

4.2. Inlet Oil Temperature Alteration. In the thermal oil heat transfer system, the heated oil will be cooled in the oil/water heat exchanger to heat water and generate steam. Then, the cooled oil will return to the entry of solar collector as a new beginning point for a circle. Therefore, the performance of cooling system will affect the output parameters of heat transfer oil directly. Figure 8 shows the changes of output oil temperature with the inlet temperature from $258^{\circ} \mathrm{C}$ to $294^{\circ} \mathrm{C}$ at the interval of $3^{\circ} \mathrm{C}$. Therefore, the steady heat transfer is an important operation evaluation point.

4.3. Inlet Oil Flow Rate Alteration. Flow rate influences the heat transfer effect directly, and the output oil temperature will be reduced when increasing flow rate in the same solar radiation working condition. Therefore, adjusting the inlet flow rate is the main way to control and set the output parameters in operation. Figure 9 shows the changed output oil temperatures when changing the inlet mass flow rate in the range of $625 \mathrm{~kg} / \mathrm{s}-375 \mathrm{~kg} / \mathrm{s}$. It is clear that the rate speed from $350 \mathrm{~kg} / \mathrm{s}$ to $500 \mathrm{~kg} / \mathrm{s}$ is much faster than that in the range of $525 \mathrm{~kg} / \mathrm{s}-625 \mathrm{~kg} / \mathrm{s}$. The maximum temperature difference between $350 \mathrm{~kg} / \mathrm{s}$ and $625 \mathrm{~kg} / \mathrm{s}$ is about $80^{\circ} \mathrm{C}$.

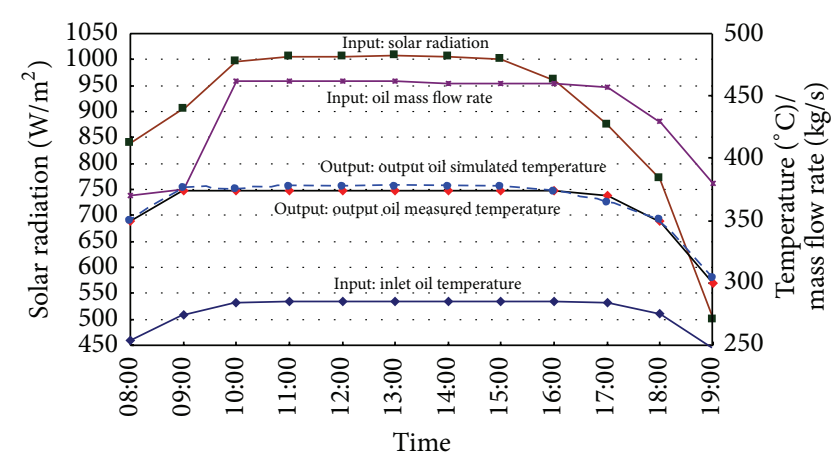

FIGURE 5: Comparison of simulated and measured results in spring working condition.

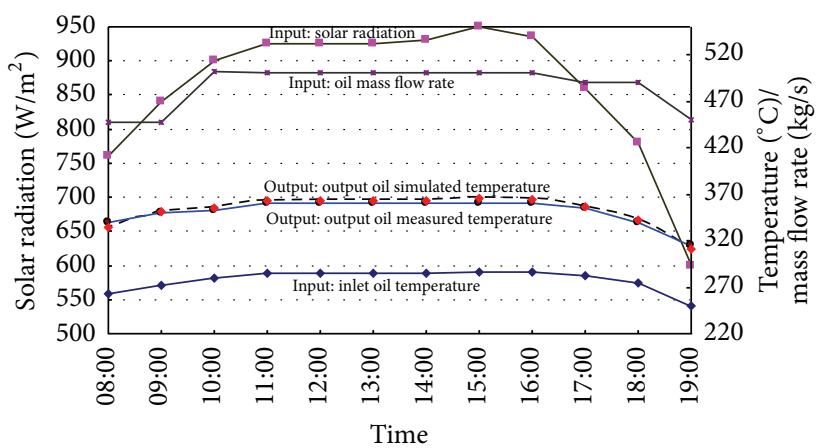

FIGURE 6: Comparison of simulated and measured results in summer working condition.

4.4. Collectors Area (Length) Alteration. As mentioned earlier, the collectors in SEGS VI power plant consisted of 50 groups of single circles. And each single circle is composed of 16 LS-2 collectors connected in series. The alteration sources of collectors' area and length are one or more collectors fault. Figure 10 shows the relation between output oil temperature and the area of collectors. The range of area and length in Figure 10 means the removed one to nine series-wound collectors (each $47 \mathrm{~m}$ length and $235 \mathrm{~m}^{2}$ ) in a single circle. The average changed temperature with every removed collector is about $8^{\circ} \mathrm{C}$. In addition, the changing speed rate from $1645 \mathrm{~m}^{2}$ to $2350 \mathrm{~m}^{2}$ is sharper than the other range. For example, the output temperature difference between $1645 \mathrm{~m}^{2}$ and $1880 \mathrm{~m}^{2}$ is $5^{\circ} \mathrm{C}$, but it is $9.4^{\circ} \mathrm{C}$ between $3525 \mathrm{~m}^{2}$ and $3760 \mathrm{~m}^{2}$.

\section{Conclusions}

In the paper, the thermal oil heat transfer process of the solar parabolic trough collector from input solar radiation to heated oil output is analyzed. The process is sorted into the three following separate sections: glass envelop heat transfer with solar radiation, absorber heat transfer with solar radiation, and absorber heat transfer with thermal oil. Then the partial differential equations are simplified by, Euler method to develop the dynamic model. The model has been validated by real operating data in typical spring and summer days. 


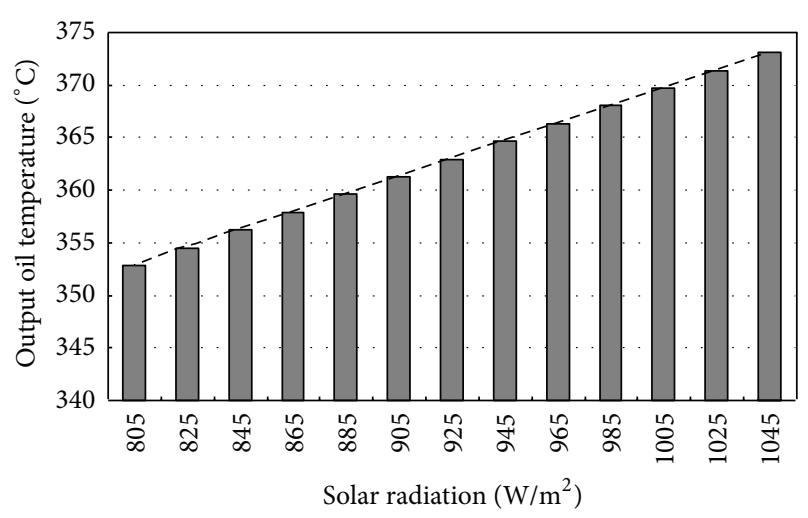

FIGURE 7: The relation between output oil temperature and solar radiation alterations.

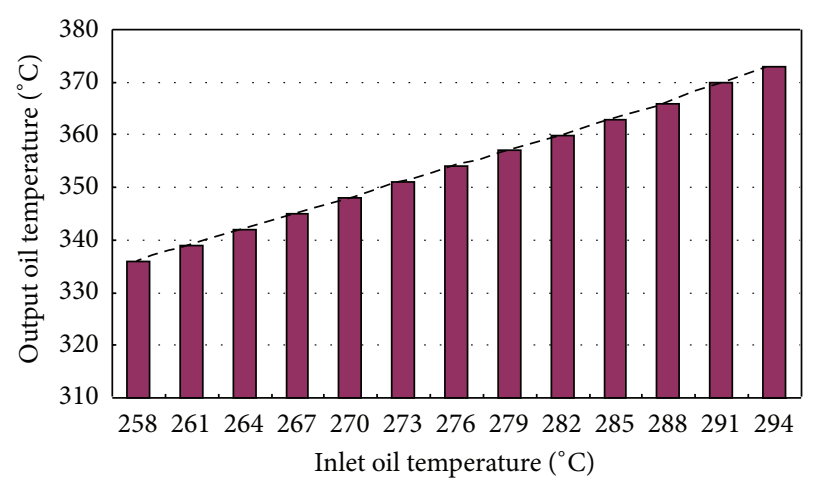

Figure 8: The relation between output oil temperature and oil inlet temperature alterations.

In the end, the alteration characteristics of different solar radiation, inlet water temperature and flow rate, and collectors' area and length are analyzed and compared with the selected normal working condition. The results can be used to research and forecast the performance of solar collectors in special working conditions.

\section{Nomenclature}

$Q_{0}$ : The absorbed heat by per unit length absorber from the solar radiation, $\mathrm{kJ}$

$Q_{0}^{\prime}$ : The absorbed heat by per unit area absorber from the solar radiation, $\mathrm{kJ}$

$Q_{1}$ : The transferred heat by per unit length absorber with the glass envelope, $\mathrm{kJ}$

$Q_{2}$ : The transferred heat by per unit length glass envelope with atmosphere, $\mathrm{kJ}$

$Q_{3}$ : The transferred heat by per unit length absorber with thermal oil, kJ

$Q_{\text {abs: }}:$ The absorbed heat by the absorber, $\mathrm{kJ}$

$Q_{g}:$ The absorbed heat by the glass envelope, $\mathrm{kJ}$

$Q_{1, r}$ : The transferred radiant heat by per unit length absorber with the glass envelope, $\mathrm{kJ}$

$Q_{1, c}$ : The transferred convectional heat by per unit length absorber with the glass envelope, $\mathrm{kJ}$

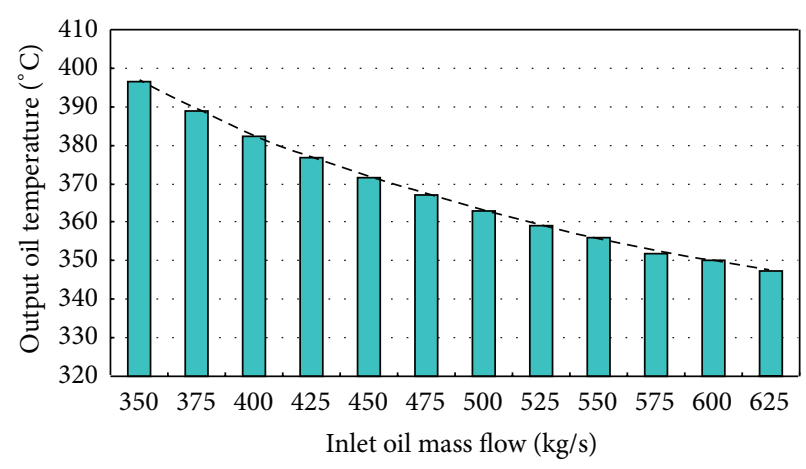

FIGURE 9: The relation between output oil temperature and inlet oil mass flow rate alterations.

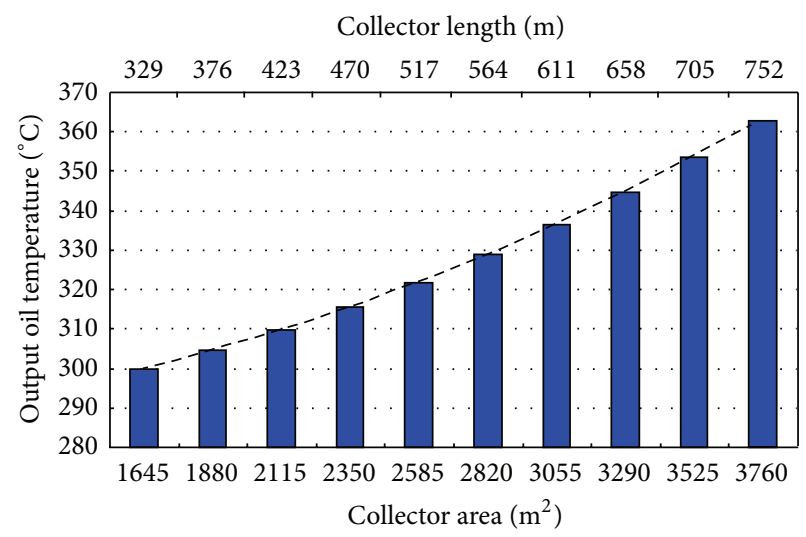

FIGURE 10: The relation between output oil temperature and collector area (length) alterations.

$Q_{2, r}:$ The transferred radiant heat by per unit length glass envelope with atmosphere, $\mathrm{kJ}$

$Q_{2, c}$ : The transferred convectional heat by per unit length glass envelope with atmosphere, $\mathrm{kJ}$

$T_{\text {abs }}$ : The temperature of the absorber, ${ }^{\circ} \mathrm{C}$

$T_{g}$ : The temperature of the glass envelope, ${ }^{\circ} \mathrm{C}$

$A_{1}$ : The cross-sectional area of the inner absorber, $A_{1}=\pi D_{1}, \mathrm{~m}^{2}$

$A_{\text {abs }}$ : The cross-sectional area of the absorber, $A_{\text {abs }}=\pi\left(\left(D_{2}-D_{1}\right) / 2\right)^{2}, \mathrm{~m}^{2}$

$A_{g}$ : The cross-sectional area of the glass envelope, $A_{g}=\pi\left(D_{g, 2}-D_{g, 1}\right)^{2} / 4, \mathrm{~m}^{2}$

$h_{1}$ : The coefficient of heat transfer between absorber and water/steam, $\mathrm{W} /\left(\mathrm{m}^{2} \cdot{ }^{\circ} \mathrm{C}\right)$

$\rho_{\text {oil }}$ : The density of thermal oil in current condition, $\mathrm{kg} / \mathrm{m}^{3}$

$\rho_{\mathrm{abs}}:$ The density of the absorber in current condition, $\mathrm{kg} / \mathrm{m}^{3}$

$\rho_{g}:$ The density of the glass envelope in current condition, $\mathrm{kg} / \mathrm{m}^{3}$

$c_{\mathrm{oil}}:$ The specific heat of thermal oil in current condition, $\mathrm{kJ} /\left(\mathrm{g} \cdot{ }^{\circ} \mathrm{C}\right)$

$c_{\text {abs }}$ : The specific heat of the absorber in current condition, $\mathrm{kJ} /\left(\mathrm{g} .{ }^{\circ} \mathrm{C}\right)$ 
$c_{g}$ : The specific heat of the glass envelope in current condition, $\mathrm{J} /\left(\mathrm{g} \cdot{ }^{\circ} \mathrm{C}\right)$

$\varepsilon_{\text {abs }}:$ The exterior emissivity of the absorber

$\varepsilon_{\mathrm{g}}$ : The inner emissivity of the glass envelope

$\alpha_{\text {gas }}$ : The thermal diffusivity of the space gas, $\mathrm{m}^{2} / \mathrm{s}$

$\beta_{\text {gas }}$ : The coefficient of cubical expansion, $1 /{ }^{\circ} \mathrm{C}$

$k_{\text {gas }}$ : The gas conductivity factor in the current condition

$\nu_{\text {gas }}$ : The coefficient of kinematics viscosity of the space gas, $\mathrm{m}^{2} / \mathrm{s}$

$g:$ The acceleration of gravity, $\mathrm{m} / \mathrm{s}^{2}$

$D_{1}$ : The inner diameter of the absorber, $\mathrm{m}$

$D_{2}$ : The exterior diameter of the absorber, $m$

$D_{g, 1}$ : The inner diameter of the glass envelope, $\mathrm{m}$

$D_{g, 2}$ : The exterior diameter of the glass envelope, $\mathrm{m}$

L: $\quad$ The length of the collector, $m$

S: $\quad$ The area of the whole collector, $\mathrm{m}^{2}$

$\operatorname{Pr}_{\text {gas }}$ : The Prandtl number of the space gas

$\mathrm{Ra}_{D_{2}}$ : The Rayleigh number of the absorber based on the exterior surface diameter

$W: \quad$ The solar direct radiation, $\mathrm{W} / \mathrm{m}^{2}$

$\theta$ : The incidence angle of the sunlight, degree

$f_{\theta}$ : The modifier of the incidence angle

$f_{s}$ : The shadow barrier factor

$f_{e}$ : The end loss factor

$\eta_{f}$ : The optics efficiency of collectors' mirrors

$\eta_{e}$ : The optics efficiency of the glass envelope and absorber

$\eta_{f f}$ : The coefficient of kinematics viscosity of the fluid (water or steam) in average fluid temperature, $\mathrm{m}^{2} / \mathrm{s}$

$\eta_{w}$ : The coefficient of kinematics viscosity of the fluid (water or steam) in absorber temperature, $\mathrm{m}^{2} / \mathrm{s}$

$f_{o}$ : The factor of operating and tracking.

\section{Acknowledgments}

The authors are grateful for the Program of China National Natural Science Fund Project (no. 51106048) and National Basic Research Program of China, 973 Project (no. 2009CB219801).

\section{References}

[1] T. A. Stuetzle, Automatic control of the 30MWe SEGS VI parabolic trough plant [M.S. thesis], The University of WisconsinMadison, Madison, Wis, USA, 2002.

[2] T. Stuetzle, N. Blair, J. W. Mitchell, and W. A. Beckman, "Automatic control of a 30 MWe SEGS VI parabolic trough plant," Solar Energy, vol. 76, no. 1-3, pp. 187-193, 2004.

[3] A. M. Patnode, Simulation and performance evaluation of parabolic trough solar power plants [M.S. thesis], The University of Wisconsin-Madison, Madison, Wis,USA, 2006.

[4] http://www.therminol.com/pages/products/vp-1.asp.

[5] S. D. Odeh, G. L. Morrison, and M. Behnia, "Modelling of parabolic trough direct steam generation solar collectors," Solar Energy, vol. 62, no. 6, pp. 395-406, 1998.

[6] M. M. Rolim, N. Fraidenraich, and C. Tiba, "Analytic modeling of a solar power plant with parabolic linear collectors," Solar Energy, vol. 83, no. 1, pp. 126-133, 2009.
[7] O. García-Valladares and N. Velázquez, "Numerical simulation of parabolic trough solar collector: improvement using counter flow concentric circular heat exchangers," International Journal of Heat and Mass Transfer, vol. 52, no. 3-4, pp. 597-609, 2009.

[8] R. Forristall, Heat Transfer Analysis and Modeling of a Parabolic Trough Solar Receiver Implemented in Engineering Equation Solver, National Renewable Energy Lab., Denver, Colo, USA, 2003.

[9] H. Price, E. Lüpfert, D. Kearney et al., "Advances in parabolic trough solar power technology," Journal of Solar Energy Engineering, Transactions of the ASME, vol. 124, no. 2, pp. 109-125, 2002. 


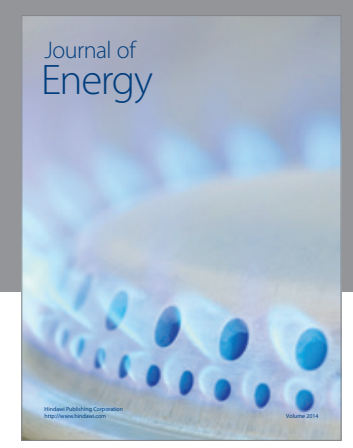

Journal of

Industrial Engineering
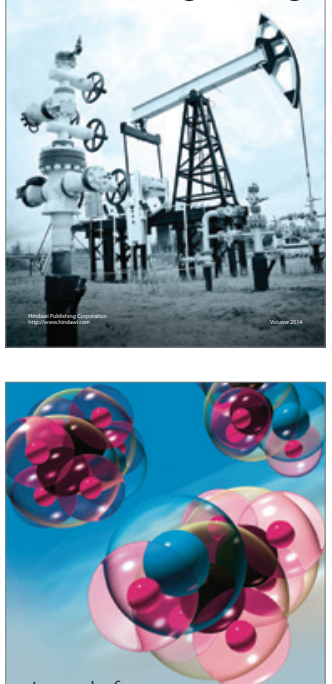

Fuels
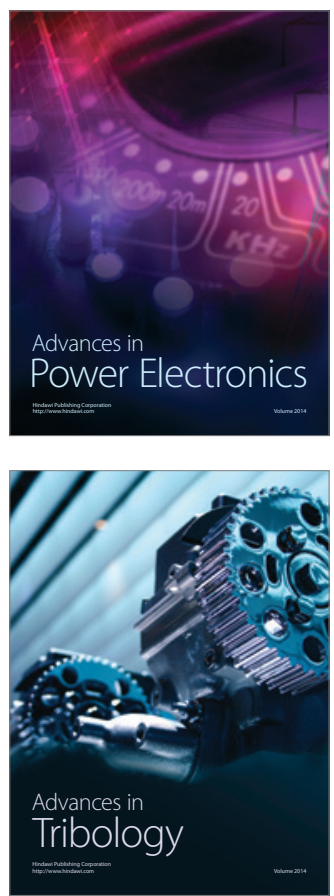

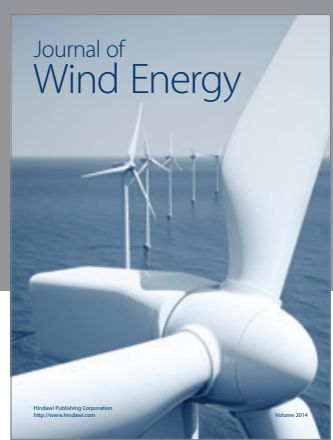

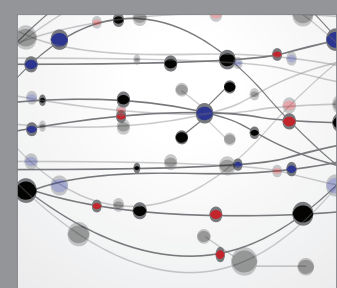

The Scientific World Journal

Submit your manuscripts at http://www.hindawi.com

Journal of

Structures
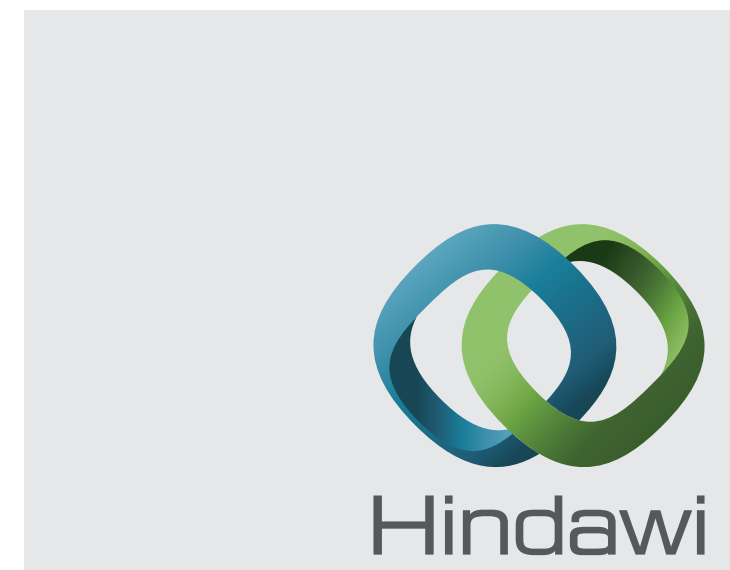

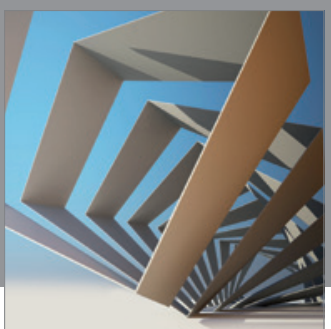

Rotating

Machinery
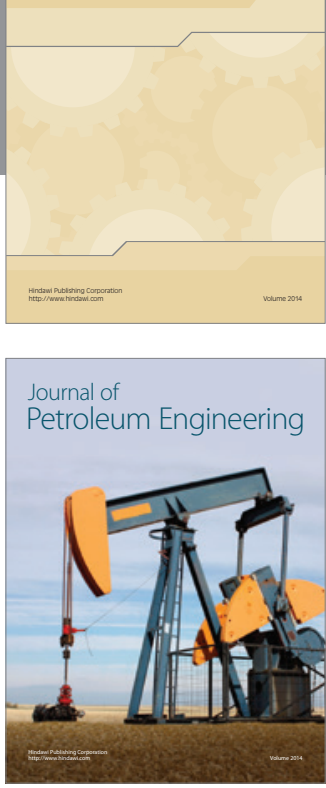

Journal of

Solar Energy
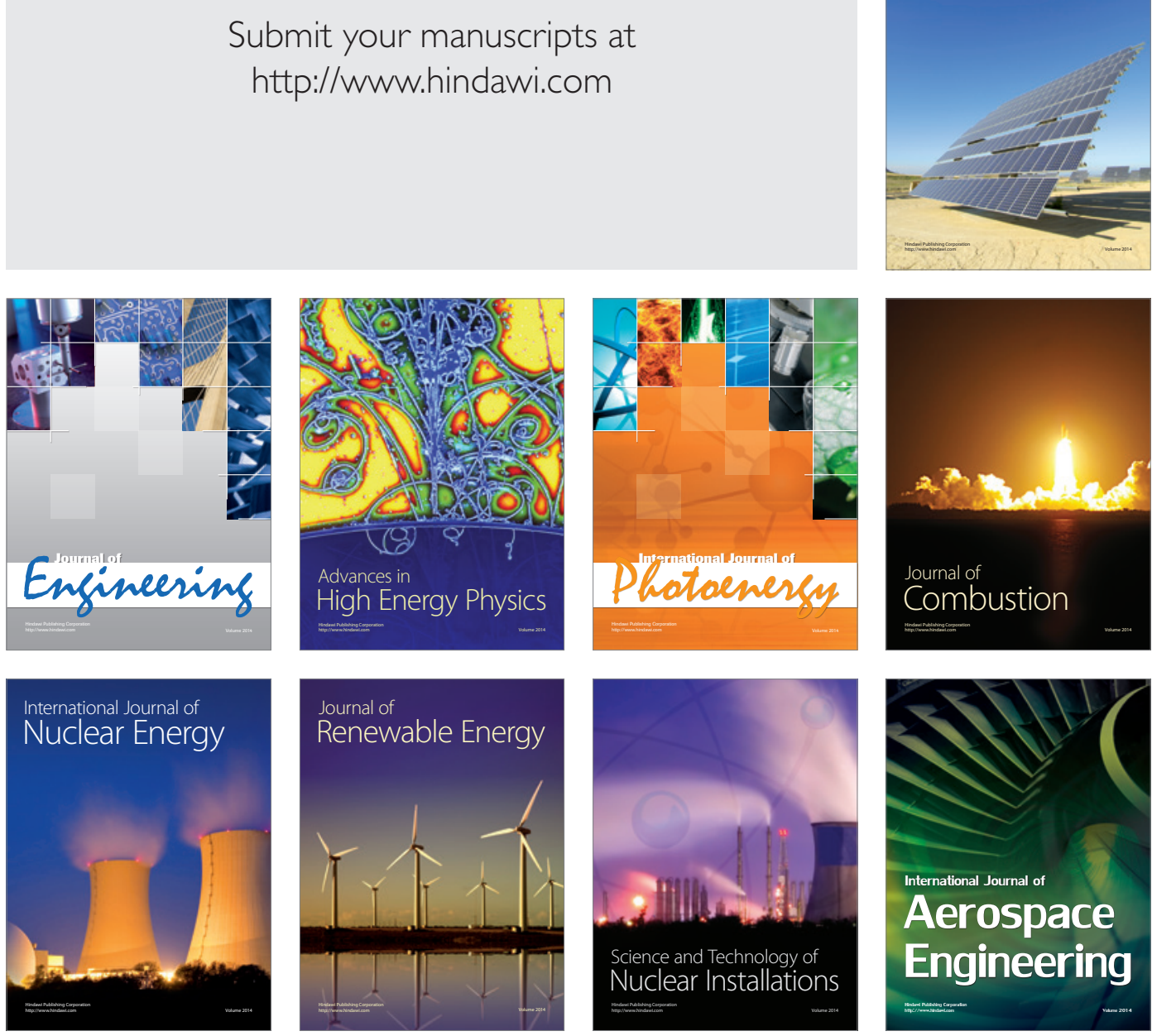